УДК 342.9

DOI https://doi.org/10.17308/vsu.proc.law.2021.1/3273

\title{
НЕКОТОРЫЕ ОСОБЕННОСТИ НОРМАТИВНОГО ПРАВОВОГО РЕГУЛИРОВАНИЯ ТРАНСПОРТНОЙ БЕЗОПАСНОСТИ РОССИЙСКОЙ ФЕДЕРАЦИИ НА СОВРЕМЕННОМ ЭТАПЕ: ПРОБЛЕМЫ И ПУТИ РЕШЕНИЯ
}

\author{
Н. А. Агаркова \\ Воронежский институт МВД России \\ Поступила в редакцию 10 января 2021 г.
}

\begin{abstract}
Аннотация: раскрывается понятие и сущность транспортной безопасности Российской Федерации, а также приводится перечень нормативных правовых актов, которые регулируют отношения в данной сфере между субъектали, ее обеспечивающили. Статья также отражает задачи, которые входят в колпетениию субъектов обеспечения транспортной безопасности. Дается подробньй анализ проблел правового регулирования, их особенностей, а также предлагаются способы их решения и устранения. Ключевые слова: транспортная безопасность, норлативное правовое регулирование, транспортная инфраструктура, транспортные средства, транспортное сообщество, акт незаконного влешательства.
\end{abstract}

Abstract: this article reveals the concept and essence of the transport security of the Russian Federation, and also provides a list of normative legal acts that regulate relations in this area between the subjects that provide it. The article also reflects the tasks that fall within the competence of the subjects of transport security. A detailed analysis of the problems of legal regulation, their features is given, and methods for their solution and elimination are proposed.

Key words: transport security, legal regulation, transport infrastructure, vehicles, transport community, act of illegal interference.

Изменения в общественной жизни людей, происходящие во всем мире, способствуют не только повышению уровня безопасности государства, общества, граждан, но и возникновению деформации, снижению защищенности и агрессии во взаимоотношениях людей. Результатом проводимых редорм нередко становятся нарушение общественного порядка, снижение экономической защищенности, уровня жизни населения, рост безработицы, алкоголизма и наркомании.

Вопрос о состоянии транспортной безопасности можно считать глобальным и общенациональным, потому что он затрагивает каждое государство и каждого гражданина.

Понятие «транспортная безопасность» впервые было упомянуто в постановлении Правительства РФ от 11 июня 2004 г. № 274 (в ред. от 25.05.2020). «Вопросы Министерства транспорта Российской Федерации» ${ }^{1}$

1 Здесь и далее все ссылки на нормативно-правовые акты приводятся по справ.-правовой системе «КонсультантПлюс». URL: http://wwwconsultant.ru

(C) Агаркова Н. А., 2021 
(подп. «3» п. 3), в котором говорилось, что Министерство транспорта Российской Федерации занимается разработкой проектов различных правовых актов, в том числе и о транспортной безопасности, после чего вносит их на рассмотрение в Правительство РФ.

Само же определение «транспортная безопасность» закреплено в Федеральном законе от 9 фревраля 2007 г. № 16-Ф3 (в ред. от 02.12.2019) «О транспортной безопасности» и представляет собой «состояние защищенности объектов транспортной инфраструктуры и транспортных средств от актов незаконного вмешательства».

Современные отечественные ученые понятие «транспортная безопасность» трактуют в разных аспектах. Например, Ю. Ф. Голиусов определяет транспортную безопасность как политическую категорию и относит ее к числу «составляющих национальной безопасности». Д. В. Карасев приравнивает транспортную безопасность к экономической составляющей страны, говоря о том, что «обеспечивая экономическую безопасность транспортных систем, можно добиться ускорения инновационного развития экономики России» ${ }^{2}$. Ю. В. Степаненко и Л. А. Басыров в своих научных работах говорят о том, что «транспортная безопасность» является юридической категорией.

Говоря о толковании термина «транспортная безопасность», возникают проблемные вопросы, так как в законодательстве также используются категории «безопасность на транспорте», «безопасность транспортного комплекса». Проблема заключается в разграничении данных понятий. Исследования данной проблемы содержатся в работах С. С. Сулашкина и А. В. Жукова. Ссылаясь на мнение ученых, наблюдается «несистемный подход к вопросу транспортной безопасности». Для решения этой проблемы, на наш взгляд, необходимо прекратить использование внешне схожих терминов с понятием «транспортная безопасность», чтобы прийти к его единообразному пониманию и вопросам обеспечения транспортной безопасности.

При определении категории «транспортная безопасность» важно учитывать различные виды угроз транспортной безопасности. Таковыми являются природные, техногенные и социальные. Самой распространенной из них является техногенная угроза, из-за которой происходит до 64 \% различных аварий и катастрофр. На долю угроз природного характера приходится около 32 \% инцидентов. Несмотря на то что самыми распространенными являются техногенные угрозы, наиболее актуальными являются социальные угрозы, к которым относится террористический акт.

В ходе совещания о мерах по повышению эфрфективности транспортной безопасности, проводимом 22 сентября 2020 г., зампредседателя Совета безопасности РФ Д. Медведев сообщил о том, что в 2019 г. российскими спецслужбами удалось предотвратить 34 террористических акта на транспорте. По данным Национального антитеррористического коми-

${ }^{2}$ Цит. по: Николаева Н. В. Транспортная безопасность : проблема определения понятия и содержания // Междунар. правовой курьер. 2016. № 1(13). С. 15-21. 


\section{Вестник ВГУ. Серия: Право}

тета, помимо этого было нейтрализовано и задержано около тысячи террористов и их пособников. В 2020 г. было зафиксировано 24 незаконных вмешательства в работу объектов транспорта и 517 угроз такого вмешательства ${ }^{3}$.

По официальным данным МВД России за период с января по октябрь 2020 г., на территории Российской Федерации зарегистрировано 1990 преступлений террористического характера ${ }^{4}$. Исходя из этого, следует, что терроризм остается угрозой для общества и государства и требует к себе пристального внимания со стороны правоохранительных органов.

Правовое регулирование деятельности, обеспечивающей транспортную безопасность в Российской Федерации, имеет огромное значение для ее субъектов. Нормативная правовая база определяет основные направления деятельности, формы и методы их осуществления, цели и фрункции, а также принадлежащие им права и обязанности.

Именно административно-правовые нормы в совокупности с юридическими средствами регулируют правовое положение, а также права и обязанности всех субъектов.

В настоящее время существует множество правовых актов, регламентирующих деятельность по обеспечению транспортной безопасности. Исходя из этого, целесообразно рассматривать нормы права в соотношении с механизмом регулирования в аспекте их фрункционального назначения. Поэтому важно охарактеризовать совокупность всех нормативных правовых актов, которые дают общие представления о транспортной безопасности, определяют основные направления деятельности субъектов, разграничивая при этом их полномочия.

Главенствующая роль в этом определена Основному закону страны Конституции РФ, в ст. 71 которой содержатся нормы о том, что к ведению Российской Федерации относятся такие составляющие, как экономическое развитие, федеральный транспорт, а также пути сообщения, оборона и безопасность. Имеет место то, что в Российской Федерации приняты и действуют нормативные правовые акты, которые направлены на пресечение и устранение конкретных угроз безопасности.

Правовые акты, которые непосредственно регулируют деятельность субъектов, обеспечивающих безопасность на объектах транспорта:

172 1. Федеральный закон Российской Федерации от 9 февраля 2007 г. № 16-Ф3 (в ред. от 02.12.2019) «О транспортной безопасности».

2. Федеральный закон от 7 фревраля 2011 г. № 3-Ф3 (в ред. от 06.02.2020) «О полиции».

3. Указ Президента РФ от 31 марта 2010 г. № 403 «О создании комплексной системы обеспечения безопасности населения на транспорте».

4. Постановление Правительства РФ от 15 ноября 2014 г. № 1208 (в ред. от 16.09.2020) «Об утверждении требований по соблюдению транс-

${ }^{3}$ Официальный сайт Национального антитеррористического комитета. URL: http://nac.gov.ru/ (дата обращения: 09.12.2020).

${ }^{4}$ Состояние преступности в Российской Федерации за январь-октябрь 2020 года. URL: http://мвд.pd/ (дата обращения: 09.12.2020). 
портной безопасности для фризических лиц, следующих либо находящихся на объектах транспортной инфраструктуры или транспортных средствах, по видам транспорта» и др.

Перечень ведомственных нормативно-правовых актов представлен: I

1. Приказом МВД России от 21 декабря 2015 г. № 1203 (в ред. от 26.09.2016) «О порядке выдачи органами внутренних дел Российской Федерации заключения о возможности (заключения о невозможности) допуска лиц к выполнению работ, непосредственно связанных с обеспечением транспортной безопасности».

2. Приказом Министерства транспорта РФ от 8 сентября 2014 г. № 243 (в ред. от 26.09.2016) «Об утверждении типовых дополнительных профрессиональных программ в области подготовки сил обеспечения транспортной безопасности».

3. Приказом Министерства транспорта РФ от 11 фревраля 2010 г. № 34 (в ред. от 26.02.2019) «Об утверждении Порядка разработки планов обеспечения транспортной безопасности объектов транспортной инфраструктуры и транспортных средств» и др.

Анализируя действующее законодательство можно выделить такие характерные особенности, как:

1. Универсальность законодательства, которое не содержит конкретных правовых мер к различным видам транспорта.

Каждый вид транспорта заметно отличается друг от друга, поэтому субъектам обеспечения транспортной безопасности, применяя тот или иной неспециализированный по конкретному виду транспорта нормативный правовой акт, затруднительно сделать вывод о результативности планируемых мер, которые впоследствии скажутся на фрункционировании.

2. Неочевидность взаимосвязи предусмотренных законодательством о транспортной безопасности мер с предполагаемым результатом.

В настоящее время Министерство транспорта РФ всё чаще акцентирует внимание на выявление взаимосвязи между существующими правовыми нормами, ориентированными на обеспечение транспортной безопасности, с конечным результатом.

Существующая тенденция показывает, что законы исполняются, 173 средства затрачиваются, при этом конечный результат не достигается.

3. Большие финансовые затраты.

К числу обязательных затрат относятся: подготовка и аттестация сил, сертификация технических средств, оснащение объектов транспортной инфрраструктуры, привлечение субъектов транспортной безопасности. В Российской Федерации не закреплено правовых норм, способствующих снижению финансовых затрат. В результате чего единственным способом, направленным на компенсацию понесенных затрат и издержек становится увеличение стоимости услуг.

4. Разногласия между российскими и иностранными перевозчиками по созданию условий обеспечения транспортной безопасности. 
Существуют неравные условия из-за увеличения стоимости услуг отечественных перевозчиков, что негативно влияет на конкуренцию российских компаний.

Говоря о существующих проблемах в области нормативно-правового регулирования в сфере транспортной безопасности, можно выделить такие, как:

- законодательные акты не в полной мере раскрывают сущность и особенности проводимых мер в целях обеспечения защиты объектов транспортной инфраструктуры от актов незаконного вмешательства, а также общественного порядка и безопасности;

- противоречие правовых норм друг другу.

Таким образом, решить данные проблемы возможно с помощью переработки и уточнения некоторых положений.

Рассматривая Федеральный закон «О транспортной безопасности», можно выделить ряд проблемных вопросов.

Во-первых, в данном законе понятийный аппарат недостаточно широко и понятно раскрывает значение определения. Говоря о термине «транспортная безопасность», следует отметить, что его сущность раскрыта не в полной мере. На наш взгляд, законодатель должен учитывать, с помощью каких мер это осуществляется.

Во-вторых, понятие «подразделения транспортной безопасности», определяющееся как «осуществляющие защиту объектов транспортной инфраструктуры и транспортных средств от актов незаконного вмешательства (в том числе на основании договора с субъектом транспортной инфраструктуры), подразделения ведомственной охраны федеральных органов исполнительной власти в области транспорта и (или) аккредитованные для этой цели в установленном порядке юридические лица ${ }^{5}$, не совсем понятно, а именно: какие юридические лица здесь имеются в виду.

В-третьих, существуют противоречия не только внутри закона, но и между отдельными нормами законодательства. Так, в ст. 12.2 Федерального закона «О транспортной безопасности» указано, что на субъектов транспортной инфраструктуры (юридические лица, индивидуальные предприниматели и физические лица) и перевозчиков (юридические лица или индивидуальные предприниматели) возложена организация досмотра, наблюдения и собеседования в целях обеспечения транспортной безопасности. Проблема заключается в том, что отсутствует порядок проведения указанных мероприятий, а также вид проводимого досмотра. Если в данном случае речь идет об административном досмотре, регламентированном Кодексом Российской Федерации об административных правонарушениях ${ }^{6}$, то возникает существенное противоречие. Административный досмотр является мерой административного принуждения и

${ }^{5} \mathrm{O}$ транспортной безопасности : фредер. закон от 9 февраля 2007 г. № 16-ФЗ (в ред. от 02.12.2019).

${ }^{6}$ Кодекс Российской Федерации об административных правонарушениях : dpeдер. закон от 30 декабря 2001 г. № 195-ФЗ (в ред. от 15.10.2020). 
проводится в целях пресечения административного правонарушения и установления личности, а лицами его проведения не являются субъекты транспортной инфраструктуры и перевозчики.

Предлагаем следующее решение выявленных проблем нормативно-правового регулирования:

1. В целях наиболее полного и широкого для правоприменителя понимания термина «транспортная безопасность» считаем целесообразным расширить его трактовку как «состояние защищенности объектов транспортной инфраструктуры и транспортных средств от актов незаконного вмешательства, посредством организации и осуществления субъектами транспортной безопасности комплекса специальных мер информационного, технического, охранного характера в области обеспечения общественного порядка и безопасности на различных видах и объектах транспорта».

2. Понятие «подразделения транспортной безопасности» конкретизировать посредством расширения и закрепления в нем системы субъектов, обеспечивающих транспортную безопасность: «осуществляющие защиту объектов транспортной инфраструктуры и транспортных средств от актов незаконного вмешательства и аккредитованные для этой цели в установленном порядке юридические лица, в обязательном порядке прошедшие аттестацию - подразделения ведомственной охраны федеральных органов исполнительной власти в области транспорта, ФГП «Ведомственная охрана железнодорожного транспорта Российской Федерации», ФГУП «Управление ведомственной охраны Министерства транспорта Российской Федерации, ФГУП «Охрана» Росгвардии, Главное управление на транспорте МВД России, Служба авиационной безопасности, подразделения транспортной безопасности, непосредственно обеспечивающие транспортную безопасность объектов транспортной инфраструктуры или транспортных средств «Росморпорт», подразделения транспортной безопасности, созданные в субъектах транспортной инфраструктуры.

3. Указать, какой именно вид досмотра проводится, и закрепить перечень субъектов транспортной безопасности, которые вправе его осуществлять. На наш взгляд, таковым является досмотр фризических лиц, транспортных средств, грузов, багажа, почтовых отправлений, ручной клади, личных вещей и других материальных объектов. Субъекты, которые вправе его осуществлять:

- работники, обеспечивающие транспортную безопасность на объекте транспортной инфраструктуры или транспортного средства;

- работники транспортной инфраструктуры, включенные в состав быстрого реагирования;

- работники, осуществляющие наблюдение в целях обеспечения транспортной безопасности;

- работники, управляющие транспортными средствами в целях обеспечения безопасности.

Основу транспортной системы составляют фредеральный транспорт, пути сообщения, куда входят железнодорожный, воздушный, морской, речной, трубопроводный транспорт и федеральные автомобильные доро- 


\section{Вестник ВГУ. Серия: Право}

ги. Исходя из этого социальной функцией государства является обеспечение безопасности перемещения людей, товаров и грузов на всех видах транспорта. Задачей Российской Федерации и ее субъектов является решение задач, связанных с общественным порядком, поддержанием обороноспособности, экологической безопасности, ликвидации последствий стихийных бедствий, а также техногенных катастрофр (ст. 72 Конституции РФ).

Важно помнить, что на формирование уровня транспортной безопасности Российской Федерации влияет состояние правопорядка и общественной безопасности на всех объектах транспортной инфраструктуры в целом. Лишь тогда можно судить о том, правильно или нет государство, совместно с компетентными субъектами, реализует свою политику в данной сорере ${ }^{7}$.

Поэтому, для того чтобы стабилизировать ситуащию в данном направлении, было принято распоряжение Правительства РФ от 22 ноября 2008 г. № 1734-р (в ред. от 12.05.2018) «О транспортной стратегии РФ на период до 2030 года». В данном нормативном акте закреплены основные цели, которые помогут достичь высокого уровня безопасности на объектах транспорта.

Еще одной из важнейших задач следует считать разработку и дальнейшую реализацию мер, обеспечивающих конституционные права и свободы граждан от противоправных посягательств, а также пресечение преступных проявлений. Аппаратом МВД России в рамках этого был разработан и предложен Минтрансу России перечень программных предложений:

1) разработка технических регламентов для обеспечения безопасности дорожного движения, где необходимо ссылаться на международную практику по оснащению автомобильных дорог современными техническими устройствами;

2) создание общероссийской базы транспортных средств, особое внимание при этом уделять наличию лицензий на осуществление перевозок детей, транспортировку опасных грузов и др.;

3) закрепление правовой базы, регулирующей порядок владения транспортными средствами, которые занимаются перевозкой пассажиров, грузов;

4) внедрение и применение современных инновационных технологий, модернизация парка специальных вагонов ФОИВ и оснащение поездов системой ГЛОНАСС и др.

Доктринальные проблемы, которые касаются вопросов транспортной безопасности, по-прежнему остаются нерешенными и анализируются учеными и государством. В целях их решения, на наш взгляд, необходимо также стремиться к установлению общности законодательства со смежными международными правовыми актами. В данном случае целесообразно применить такой способ, как имплементация норм междуна-

${ }^{7}$ См.: Субочев В. В. Законные интересы в механизме правового регулирования / под ред. А. В. Малько. М., 2007. 
родного права о транспортной безопасности в законодательство Российской Федерации.

На государственном уровне необходимо осуществлять деятельность по разъяснению законодательно закрепленных мер, обеспечивающих транспортную безопасность, их обоснованности и необходимости осуществления, а также оперативно реагировать на возникающие проблемы законодательства, в том числе и на проблемы фринансового обеспечения субъектов транспортной инфраструктуры. В связи с этим предлагаем следующий алгоритм проведения данной деятельности:

1) выявление тех фрундаментальных ценностей и целей, которыми обладает действующая нормативно-правовая основа;

2) установление круга лиц, а также общественных отношений, в которые они вступают при осуществлении деятельности;

3) определение конфрликта интересов между субъектами;

4) анализ действующего законодательства обеспечения транспортной безопасности, а также выявление в нем существующих пробелов, коллизий;

5) вызовы нормативно-правового регулирования (правовое проблемное поле);

6) поиск оптимальных способов, а также разработка методологических приемов для решения и устранения возникших проблем правового регулирования;

7) воплощение способов решения проблем посредством юридических и технических методов;

8) принятие нормативного акта в соответствии с существующими процедурами.

Таким образом, исходя из толкования понятия «транспортная безопасность» и рассмотрев правовые основы ее обеспечения, следует отметить, что транспортная безопасность обеспечивается деятельностью ее субъектов, к которым относится широкий перечень органов исполнительной власти, посредством реализации мер, направленных на предупреждение угроз совершения противоправных посягательств на объекты транспортной инфраструктуры. Нормативная правовая база в данном случае выступает центральным элементом системы обеспечения и поддержания транспортной безопасности.

Результат работы будет зависеть от ответственного соблюдения и применения указанных правовых норм всеми субъектами, имеющими высокий уровень компетенции в рассматриваемой деятельности. Государство должно применять системный подход к реализации законодательно закрепленных мер в данной области.

Воронежский институт МВД России

Агаркова Н. А., адъюнкт

E-mail: agarckova.natali2016@yandex.ru
Voronezh Institute of the Russian Ministry of Internal Affairs

Agarkova N. A., Adjunct

E-mail: agarckova.natali2016@yandex.ru 